ANO $9 \bullet$ EDIÇÃO ESPECIAL • NÚMEROS $16 / 17 \bullet 2012 \bullet$ ORGANICOM

ESPACO ABERTO
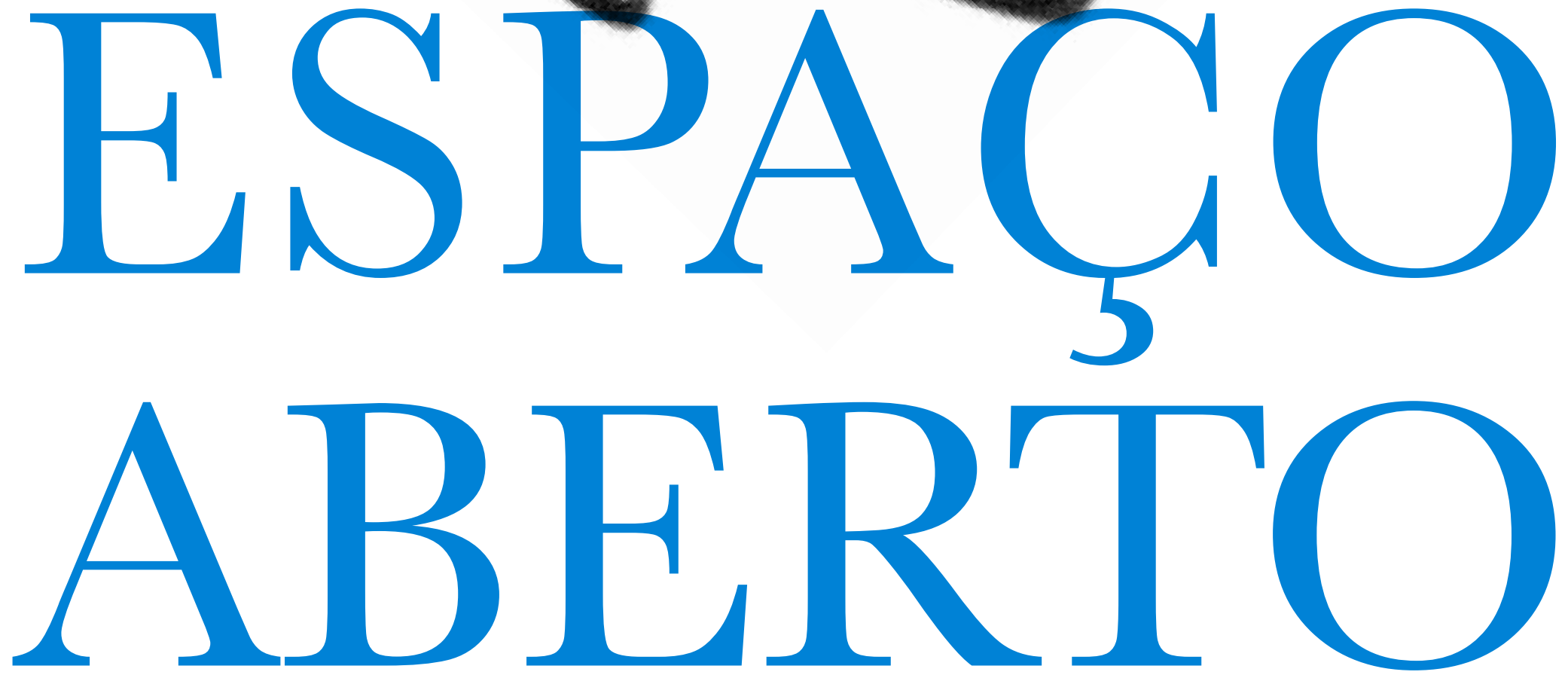


\section{Comunicação da ciência: \\ rumo a uma teoria da divulgação científica}

Science communication:

towards a theory of scientific disclosure

Comunicación de la ciencia:

rumbo a una teoría de la divulgación científica

\section{Isaac Epstein}

- Doutor em Ciências da Comunicação (1991) pela Escola de Comunicações e Artes da Universidade de São Paulo (ECA-USP)

- Mestre em Filosofia (1983) pela Faculdade de Filosofia, Letras e Ciências Humanas da Universidade de São Paulo (FFLCH-USP)

- Graduado em Engenharia Civil pela Universidade de São Paulo (1950)

- $\quad$ Consultor ad hoc do Coordenação de Aperfeiçoamento de Pessoal de Nível Superior (Capes) e parecerista sobre concessão de bolsas da Fundação de Amparo à Pesquisa do Estado de São Paulo (Fapesp)

- Professor visitante da Universidade de Salamanca, Espanha

- Docente do PósCom - Umesp (1987-2009), com enfasê em teorias da comunicação de massa, comunicação da saúde e divulgação científica

- E-mail: isaacepstein@uol.com.br 


\section{Resumo}

Propõe-se uma perspectiva e um quadro de referência para se examinar e compreender a problemática da comunicação pública da ciência. São sugeridas algumas dimensões disciplinares para assinalar as diferenças entre o discurso interpares (comunicação primária) da ciência e o discurso da comunicação pública da ciência (comunicação secundária). A partir dessas dimensões formula-se uma matriz multidisciplinar que mostra como algumas questões e obstáculos à comunicação pública da ciência podem emergir e ser interpretados mais como divergências estruturais necessárias entre esses dois discursos, vistos agora como diferentes "estilos profissionais", em vez de, apenas, "disfunções", pressões conjunturais ou diferenças pontuais entre cientistas e divulgadores. Essa interpretação certamente melhorará a compreensão mútua entre cientistas e jornalistas.

PALAVRAS CHAVE: DIVULGAÇÃO CIENTÍFICA • COMUNICAÇÃO PRIMÁRIA • COMUNICAÇÃO SECUNDÁRIA • MATRIZ MULTIDISCPLINAR

\section{Abstract}

This text is a proposal of a perspective and of a reference table for examination and comprehension of the problem of public science communication. Certain disciplinary dimensions are suggested to point out the differences between the inter-peers discussion (primary communication) of science and the public discussion of public science communication (secondary communication). Using these dimensions one develops a multidisciplinary matrix that shows how some issues and obstacles for public communication science can emerge and be construed more as necessary structural divergences between these two discussions, now seen as different "professional styles", instead of only "dysfunctions", circumstantial pressures or pointed differences between scientists and disclosure agents. This construal will certainly improve the mutual understanding between scientists and journalists.

KEYWORDS: SCIENTIFIC DISCLOSURE • PRIMARY COMMUNICATION • SECONDARY COMMUNICATION • MULTIDISCIPLINARY MATRIX

\section{Resumen}

Se propone una perspectiva y un cuadro de referencia para que se examine y comprenda la problemática de la comunicación pública de la ciencia. Son sugeridas algunas dimensiones disciplinares para señalar las diferencias entre el discurso interpares (comunicación primaria) de la ciencia y el discurso de la comunicación pública de la ciencia (comunicación secundaria). A partir de esas dimensiones se formula una matriz multidisciplinar que muestra cómo algunas cuestiones y obstáculos a la comunicación pública de la ciencia pueden emerger y ser interpretadas más como divergencias estructurales necesarias entre esos dos discursos, vistos ahora como diferentes "estilos profesionales", en lugar de, apenas, "disfunciones", presiones coyunturales o diferencias puntuales entre cientistas y divulgadores. Esa interpretación ciertamente mejorará la comprensión mutua entre cientistas y periodistas.

PALABRAS CLAVE: DIVULGACIÓN CIENTIFICA • COMUNICACIÓN PRIMARIA • COMUNICACIÓN SECUNDARIA • MATRIZ MULTIDISCPLINAR 
A comunicação da ciência se subdivide em dois discursos distintos que convergem em alguns aspectos e divergem em outros: a comunicação interpares, também chamada de comunicação primária (CP) e a comunicação pública ou divulgação científica também conhecida por comunicação secundária (CS).

Todavia, o fluxo da comunicação entre CP e CS não é simétrico, pois, enquanto a CP é fonte indispensável à operação da CS, a CS não informa necessariamente a CP. O discurso interpares dos cientistas é stricto sensu autômomo ${ }^{1}$. Em seu contexto interno a produção do conhecimento científico, suas teorias e os experimentos decorrentes, suas confirmações ou falsificações expressas na $\mathrm{CP}$, sua aceitação ou rejeição pela comunidade de cientistas, é o que se costuma chamar de contexto da justificação. A autonomia deste contexto é todavia, assumida pela epistemologia hegemônica pré-kuhniana, ainda muito influente entre os cientistas. Atualmente, muitas críticas têm sido dirigidas a essa posição, principalmente no âmbito do chamado "construtivismo social"2.

A CP (interpares) e a CS (pública) são expressas em dois discursos que podem: dispor de periódicos especializados (CP) ou serem inseridos na mídia massiva - jornais, livros de divulgação científica, rádio, internet, museus de ciência etc. (CS). Em realidade, as publicações formam um contínuo ${ }^{3}$, das mais "puras", destinadas apenas a especialistas, às híbridas, contendo espaços destinados à $\mathrm{CP}$ e à $\mathrm{CS}$, até as publicações massivas, destinadas a um público jejuno em ciência. O esquema a seguir designa os três atores paradigmáticos como: produtores (CP), divulgadores (CP > CS) e público (CS). I1 é a interface produtores x divulgadores e I2, a interface divulgadores $\mathrm{x}$ publico:

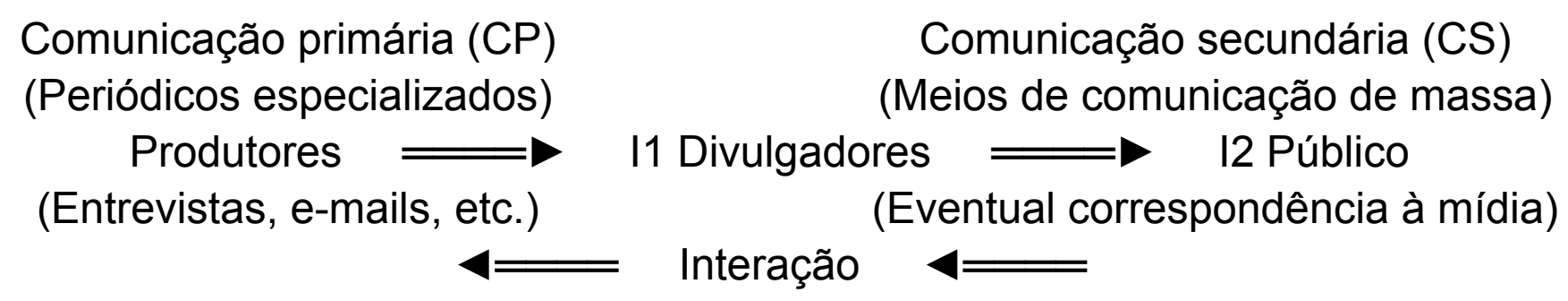

O trânsito da comunicação primária para a secundária configura um campo de estudos e práticas correlatas onde se desdobram, sob a circunscrição das ciências da comunicação, dimensões multidisciplinares que serão discriminadas na sequência deste trabalho.

\footnotetext{
1 Em verdade, em alguns casos, a CS pode exercer alguma influência (contexto da descoberta) sobre a CP, uma vez que a opinião pública pode responder à CS, no sentido de ter uma atitude sobre a oportunidade de determinadas pesquisas, seu custo-benefício, visibilidade das fontes produtoras do conhecimento científico etc. De qualquer forma, essa assimetria na comunicação entre CP e CS é causa de uma ascendência e algum poder dos produtores sobre os divulgadores, uma vez que os segundos são funcionalmente dependentes dos primeiros.

${ }^{2}$ O construtivismo social afirma que o conhecimento científico também é o produto de vários fatores sociais e não o resultado de uma investigação objetiva na qual os procedimentos são independentes de nossos interesses sociais (Collins; Evans, 2002).

${ }^{3}$ Os veículos de comunicação primária são as revistas de cada especialidade científica. Os de comunicação secundária são destinados ao grande público. Uma categoria intermediária se destina a um público que já possui alguma cultura científica ou universitária. Exemplos, entre nós, são as revistas Ciência Hoje e Scientific American do Brasil. Uma outra categoria, a que pertencem as revistas Science e Nature, publicam artigos de comunicação primária, destinados aos especialistas, mas incluem também matérias de interesse mais geral, como notícias ou editorias sobre política científica, temas de sociologia da ciência, como desvios de conduta na ciência, atuação científica de grupos minoritários etc.
} 


\section{SISTEMA DA CIÊNCIA}

A comunicação secundária (CS), isto é, a divulgação científica ou popularização do conhecimento científico, pode tanto ser feita pelo divulgador ou jornalista científico, mediador entre o cientista e o público, como pelo próprio cientista, que assume então o papel do divulgador.

Alguns autores, como John Brookman (1995), falam daqueles cientistas que, evitando o "terceiro homem", (o jornalista científico) divulgam a ciência e expressam seus mais profundos pensamentos de modo acessível ao público leigo. A competência da atuação dos pensadores da "terceira cultura”, assim denominada por Brockman, como Richard Dawkins (1998) Carl Sagan (1995), Martin Gardner (1996) e outros, se deve não só à sua competência profissional, mas também à sua habilidade em escrever para um público já razoavelmente alfabetizado em ciência. Entre nós o físico Marcelo Gleiser (1997) e outros encarnam este papel com sucesso. O diagrama acima pertence a um sistema mais amplo que poderíamos chamar de "sistema da ciência" - CP>CS - e que de uma maneira gráfica poderia ser representado pelo quadro a seguir:

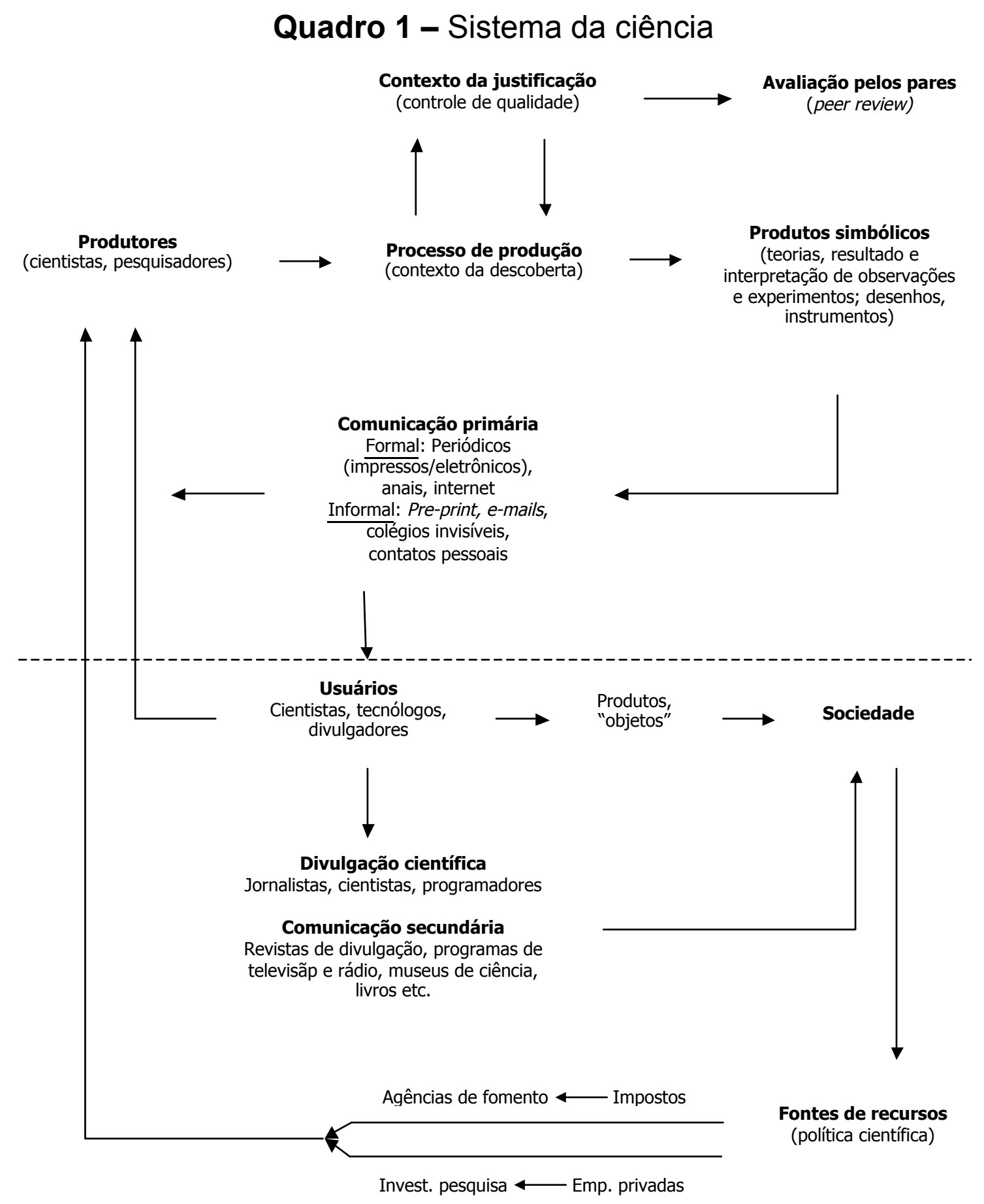




\section{MATRIZ MULTIDISCIPLINAR}

\section{Justificativa}

É fato conhecido que o desenvolvimento socioeconômico de um país guarda uma correlação positiva com sua produção científica. Esta, por sua vez depende em grande parte dos recursos alocados para essa finalidade. Ora, o Brasil apresenta um produto interno bruto (PIB) per capita cerca quatro ou pouco mais vezes menor do que o dos países mais industrializados e temos alocado, historicamente, cerca de $1 \%$ desse produto à pesquisa científica ${ }^{4}$, enquanto que os referidos países, principalmente do "grupo dos 7 "5 e alguns outros países do primeiro mundo alocam de $2 \%$ a $3 \%$ para essa finalidade.

Quanto aos princípios norteadores e gerenciadores da política científica do país, é possível admitir a influência negativa de algumas distorções nos ideários e na prática das políticas científicas adotadas. No que diz respeito aos fatores culturais, a ideia é que o incremento da alfabetização científica da população em geral possa, em alguma medida, incentivar a emergência de vocações para a pesquisa entre os estudantes, desde o primeiro até o terceiro grau. Quem sabe será possível compensar e suplementar, em alguma fração, o hardware dos recursos materiais pelo software do entusiasmo e da admiração pela ciência da população em geral, que se refletiria na emergência das referidas vocações e no apoio da população ao desenvolvimento da ciência?

Os pesquisadores científicos produzem, verificam e controlam sua própria produção e retificam ou ratificam a dos colegas. Os divulgadores procuram transmitir a ciência a um público leigo. Se por "público leigo" entendemos a totalidade da população menos os cientistas, esse público compreende toda a gama da alfabetização científica, desde os completamente jejunos e/ou avessos ao saber da ciência, os medianamente interessados, os alfabetizados cientificamente, até os próprios cientistas de especialidade diferente da divulgada.

Poucos duvidam, nos dias que correm, da necessidade de divulgar a ciência ao público. Essa necessidade vai desde a satisfação de uma curiosidade natural das pessoas em compreender a visão que a ciência apresenta do mundo, da complexidade do infinitamente pequeno, ao infinitamente grande, até a conotação política no sentido do desenvolvimento de sentimento e atitude cidadãos que é facilitado pela alfabetização científica ${ }^{6}$.

\footnotetext{
${ }^{4}$ Nesta primeira aproximação não estamos diferenciando as subvenções públicas à ciência das provenientes das fontes privadas, ou a produção científica propriamente dita da produção tecnológica.

${ }^{5}$ Constituído por Estados Unidos, Inglaterra, França, Alemanha, Japão, Canadá e Itália.

${ }^{6}$ Assume-se, geralmente, que a alfabetização científica (scientific literacy) incorpora três componentes culturais: (1) uma noção geral sobre determinados conceitos e temas substantivos da ciência; (2) uma noção sobre a natureza da atividade científica; (3) consciência do papel da ciência na sociedade e na cultura.
} 
Ora, nem o PIB ou mesmo a sua porcentagem alocada à ciência não podem ser alterados por uma vontade unilateral dos poderes executivo ou legislativo. O PIB representa o próprio desenvolvimento econômico do país, função de muitas contingências políticas nacionais e globais que não dependem apenas da ação dos governantes. A parcela do PIB alocada a ciência e tecnologia (C\&T), aparentemente mais facilmente remanejada pelo governo, depende de um delicado equilíbrio com outras prioridades igualmente prementes.

Como alguns outros países emergentes, não temos suficiente pesquisa e produção científica, porque ainda não somos um país rico e ainda não o somos até mesmo porque não investimos suficientemente em ciência. Será possível romper, pelo menos em parte, esse impasse?

Uma questão é então, oportuna: será a produção científica uma função univocamente correlacionada aos recursos materiais a ela alocados? Não existirão outros fatores de ordem gerencial e administrativa e outros ainda, de ordem cultural, que poderão potencializar os relativamente parcos recursos destinados à pesquisa científica?

Sabemos que as paixões nacionais, tanto as artísticas, como o balé na Rússia, a música clássica na Alemanha, o teatro na Inglaterra, a ópera na Itália e a pintura na França, quanto as esportivas, como a tourada na Espanha a ginástica olímpica nos países do leste europeu ou o futebol no Brasil, contam como patrimônio cultural exemplar desses países. Se as competições esportivas olímpicas ou profissionais demandam investimentos importantes, não há dúvida de que a sinergia popular provocada por essas paixões suplementam de forma efetiva o trabalho para que se consiga o nível de excelência necessário para fazer uma boa figura no contexto das competições internacionais.

\section{Quadro 2 - Paixões nacionais}



Fonte: Miami Herald 
O futebol impregna a alma da maioria da população brasileira de todas as camadas sociais. Desde a diversão dos garotos da várzea, até às inúmeras associações esportivas por este país afora, a sinergia ocasionada por essa paixão coletiva acalentaria, cedo ou tarde, a conquista do hexacampeonato mundial.

Não iremos tão longe no caso da ciência, onde, certamente, são necessários vultosos recursos materiais variáveis de setor a setor. Nem será tão fácil tentar despertar a vocação, a simpatia e o gosto pela carreira de pesquisador científico no jovem estudante.

Erradicar o analfabetismo científico (para o que a divulgação científica bem feita pode ser um fator importante) é uma das vias seguras para incentivar as vocações à carreira de pesquisador científico e também engajar a participação efetiva da população na problemática do desenvolvimento científico e tecnológico. Atualmente há uma necessidade crescente da participação do público num debate sobre os usos da ciência, sobre as opções tecnológicas mais adequadas para o desenvolvimento autossustentado, avaliação dos alimentos transgênicos, questões ligadas à medicina e à saúde, problemas ambientais e energéticos etc.

As grandes organizações produtoras do saber científico também têm necessidade de ascender a certa visibilidade, até mesmo para justificar os recursos públicos ou privados a elas destinados. Por outro lado, a ciência e a tecnologia contribuem de modo decisivo para a modernização dos processos de produção e, consequentemente, inserir o país num mercado global.

A divulgação científica envolve um grande número de fatores. Além de um conhecimento geral, não necessariamente especializado, o comunicador deve deter uma razoável alfabetização científica. (Jacobi; Schiele, 1988). Esse tipo de comunicação, em suas várias modalidades (mídia impressa, museus de ciência, livros didáticos, programas de rádio e televisão, internet etc.) enfrenta vários obstáculos de natureza tanto endógena como exógena (Roqueplo, 1977).

Dentre estes obstáculos se salienta a dificuldade do comunicador em "traduzir" para uma linguagem ordinária e acessível ao público leigo os conteúdos das pesquisas científicas, geralmente elaboradas e transcritas em códigos e linguagens específicos apenas acessíveis aos iniciados. Esse comunicador terá duas interfaces: uma com o conhecimento científico e outra com o público. Poderá sofrer críticas dos dois lados. Dos especialistas, que podem the atribuir pouca fidelidade e competência em sua tarefa, e, por outro, do público leigo, que pode achar sua comunicação pouco compreensível. Como se pode imaginar, o ponto ótimo para contornar esses obstáculos, nas duas interfaces, não é de fácil acesso e demanda preparo e dedicação por parte do comunicador.

Os cursos correlatos de divulgação e jornalismo científico se multiplicam na graduação, na extensão, no mestrado e no doutorado. Todavia, além de seus aspectos conjunturais, anedóticos e mesmo políticos, pouco se tem produzido sobre o aspecto teórico propriamente dito dessa 
prática. Quais as origens multidisciplinares de uma possível teoria da divulgação científica? Sabemos que elas existem na linguística, nas teorias da tradução, na sociologia da ciência, na epistemologia, na semiótica, nas teorias da mídia massiva, na teoria da informação etc.

A divulgação científica representa um legítimo campo das ciências da comunicação que, para ser adequadamente estudado, demanda uma visão multidisciplinar. Nosso objetivo neste texto é propor uma perspectiva e uma matriz multidisciplinar para examinar a problemática da comunicação pública da ciência e da relação entre cientistas, divulgadores e público. Trata-se de fazer com que as questões, os obstáculos e as dificuldades possam emergir e ser interpretados mais como inadequações e incongruências entre diversas 'formas de vida' ou estilos profissionais (Honderich, 1995, p. 228) do que apenas como disfunções éticas ou pressões conjeturais sobre os agentes envolvidos na comunicação pública da ciência.

\section{Objetivos}

Como mencionamos, a comunicação primária e a secundária são processos que configuram um campo de estudos, teorias e práticas que se desdobram em várias dimensões que podem ser esquematizadas por meio de uma matriz multidisciplinar. $O$ presente trabalho visa apresentar essa matriz, na qual os discursos da ciência e da divulgação podem ser diferenciados em diversas dimensões disciplinares. Com isso, cientistas, jornalistas e estudiosos de divulgação científica em geral poderão perceber que muitos dos obstáculos e das disfunções do trânsito da comunicação primária à comunicação secundária poderão ser mais bem superados se entendidos como diferenças "naturais" entre esses dois discursos.

Nosso principal objetivo é, portanto, contribuir para um entendimento mais produtivo das disfunções da divulgação científica. Sem qualquer pretensão quanto a resolver essas disfunções, algumas talvez insolúveis, é importante o entendimento mútuo de jornalistas e cientistas de que seus respectivos discursos comportam diferenças e divergências porque isso faz parte necessária de suas respectivas características. A compreensão desse fato, no fundo, a compreensão das diferenças do discurso do "outro" como necessariamente diferente do discurso próprio, sem dúvida contribuirá para a superação de determinadas incompreensões mútuas.

\section{Hipóteses}

Partimos da hipótese de que os discursos da comunicação primária (interpares) da ciência e da comunicação secundária (com o público) se diferenciam segundo algumas dimensões, as quais, por sua vez, compreendem algumas subdivisões. Essas diferenças não ocorrem gratuitamente, mas são devidas a várias razões, como objetivos, público destinatário e a natureza da comu- 
nicação desses discursos. Por isso, essas dimensões podem ser mais bem avaliadas quando interpretadas por diferentes disciplinas. Essas diferenças, por sua vez, devem ser explicadas a partir das razões acima, o que, para algumas delas, será feito após apresentação da matriz multidisciplinar que nada mais é do que um quadro referenciando as dimensões e subdivisões já mencionadas.

Os obstáculos e as disfunções da divulgação científica compreendidos como devidos a diferenças estruturais entre os respectivos discursos pode favorecer, na medida do possível, sua superação. Os próprios fatores de uma percepção negativa dos cientistas pelos jornalistas, e o inverso ${ }^{7}$, ao invés de serem atribuídos a características seja idiossincráticas de determinados atores, seja da própria deformação profissional dessas categorias podem, como dissemos, ser entendidas como diferenças, até certo ponto, "naturais" entre naturezas diferentes de dois discursos: da comunicação primária e secundária da ciência.

A consciência desse fato é um passo importante para melhorar a compreensão recíproca dos atores envolvidos. No fundo se trata de respeitar a diferença e, a partir desse respeito e de uma compreensão mútua dessa diferença, achar um caminho para a saída do impasse.

A matriz apresentada na sequência é, pois, um recurso heurístico capaz de sugerir temas e campos de pesquisa com características diferenciadas da comunicação primária e secundária. Neste trabalho esboçamos a descrição de alguns desses campos.

\begin{tabular}{|c|c|c|c|}
\hline DIMENSÕES & $\begin{array}{c}\text { COMUNICAÇÃO } \\
\text { PRIMÁRIA }\end{array}$ & REFERÊNCIAS & REFERÊNCIAS \\
\hline \multicolumn{4}{|l|}{ (0) ONTOLÓGICA } \\
\hline Objetos & $\begin{array}{l}\text { Objetos correspon- } \\
\text { dem a conceitos } \\
\text { científicos e às suas } \\
\text { inter-relações }\end{array}$ & $\begin{array}{l}\text { Objetos do senso } \\
\text { comum são "obstácu- } \\
\text { los" à ciencia (Bache- } \\
\text { lard, 1996) }\end{array}$ & $\begin{array}{l}\text { Objetos do senso } \\
\text { comum }\end{array}$ \\
\hline \multicolumn{4}{|l|}{ (L) LINGUÍSTICA } \\
\hline \multirow[t]{2}{*}{ Funções da linguagem } & $\begin{array}{l}\text { Linguagem especiali- } \\
\text { zada (signos específi- } \\
\text { cos, fórmulas) }\end{array}$ & Nagel, 1971 & Linguagem ordinária \\
\hline & Referencial & Jakobson, 1969, p. 129 & \begin{tabular}{|l} 
Referencial, fática, \\
emotiva, persuasiva
\end{tabular} \\
\hline
\end{tabular}

\footnotetext{
${ }^{7} \mathrm{O}$ trabalho de Hartz e Chappel, Worlds apart: how the distance between science and journalism threatens América's future (Hartz; Chappel, 1997, p. 27)), após uma extensa pesquisa que abrangeu 1.400 jornalistas e cientistas, concluiu, entre outras coisas, que: 1 . Os cientistas se queixam de que os jornalistas não compreendem questões básicas de estatística, probabilidades e risco; 2. Os jornalistas se queixam de que os cientistas estão muito envolvidos em seu esotérico jargão profissional e falham em explicar seu trabalho com simplicidade e clareza; 3 . Os cientistas dizem que a mídia simplifica exageradamente assuntos complexos; 4. Os jornalistas dizem que os cientistas não compreendem que a "novidade" é um bem perecível que precisa se mostrar relevante ao leitor ou telespectador; 5 . Ambos, cientistas e jornalistas, acham que o público norte-americano é confuso e crédulo, devido, em grande parte, ao baixo grau de alfabetização científica da população em geral.
} 


\begin{tabular}{|c|c|c|c|}
\hline \multicolumn{4}{|l|}{ S) SEMIÓTICA } \\
\hline Característica & $\begin{array}{l}\text { Idiolecto } \\
\text { (Barthes, 1971, p. } 23\end{array}$ & $\begin{array}{l}\text { Tradução intersemió- } \\
\text { tica (Jacobi e Schieli, } \\
\text { 1988) }\end{array}$ & Natural \\
\hline Signos & Unívocos por disciplina & $\begin{array}{l}\text { Eco, 1980; Marcus, } \\
1974, \text { p. } 83 \\
\end{array}$ & Equivocidade retórica \\
\hline Signos icônicos & $\begin{array}{l}\text { Gráficos, esquemas, } \\
\text { fórmulas que repre- } \\
\text { sentam funções }\end{array}$ & & $\begin{array}{l}\text { Fotografias, Figuras } \\
\text { (senso comum) }\end{array}$ \\
\hline Semiótica & Denotativa & $\begin{array}{l}\text { Hjelsmlev, 1975, } \\
\text { p. 212-219 }\end{array}$ & Conotativa \\
\hline \multicolumn{4}{|l|}{ (E) EPISTEMOLÓGICA } \\
\hline juízo & $\begin{array}{l}\text { Apodíctico } \\
\text { "Ciência normal" } \\
\text { Falsificacionismo }\end{array}$ & $\begin{array}{l}\text { Kuhn,1978, p. 57-66; } \\
\text { Popper, 1965, } 1967\end{array}$ & $\begin{array}{l}\text { Componente retórico } \\
\text { (Roqueplo,1974, p. } \\
\text { 177-194); } \\
\text { (Gregory; Miiller, } \\
\text { 1988, p. 114-117) }\end{array}$ \\
\hline \multicolumn{4}{|l|}{ (So) SOCIOLÓGICA } \\
\hline Ethos & $\begin{array}{l}\text { Imperativos Institu- } \\
\text { cionais (Crítica pós- } \\
\text {-Kuhn) } \\
\text { Publicidade restrita } \\
\end{array}$ & $\begin{array}{l}\text { Merton, } 1977 \\
\text { Segredo em ciência e } \\
\text { em divulgação científica }\end{array}$ & $\begin{array}{l}\text { Julgamento do público } \\
\text { Publicidade ampla }\end{array}$ \\
\hline Discurso competente & Legitimador & & Pode ser obstáculo \\
\hline Controle de qualidade & Pela revisão dos pares & & $\begin{array}{l}\text { Pela editoria e pelo } \\
\text { mercado }\end{array}$ \\
\hline \multicolumn{4}{|l|}{ (D) DEONTOLÓGICA } \\
\hline Normalização & $\begin{array}{l}\text { Por critérios internos } \\
\text { da comunidade de } \\
\text { cientistas }\end{array}$ & $\begin{array}{l}\text { Science, 09/07/1993, } \\
\text { p. } 149\end{array}$ & $\begin{array}{l}\text { Código de ética dos } \\
\text { jornalistas } \\
\text { (Belsey; Chadwick, } \\
\text { 1992) }\end{array}$ \\
\hline \multicolumn{4}{|l|}{ (M) MIDIOLÓGICA } \\
\hline Categoria de veículo & Especializado & & Massivo \\
\hline Conceito de Novidade & $\begin{array}{l}\text { Cultura científica (su- } \\
\text { jeita a verificação } \\
\text { ou a corroboração) }\end{array}$ & $\begin{array}{l}\text { Empirismo lógico (Na- } \\
\text { gel, 1971; } \\
\text { Popper, 1965, p. 57) } \\
\end{array}$ & $\begin{array}{l}\text { Cultura jornalística } \\
\text { (Wolf, 1990, } \\
\text { p. 222-234) } \\
\end{array}$ \\
\hline Tempo & Normal da pesquisa & $\begin{array}{l}\text { Tempo político, tem- } \\
\text { po da mídia (Collins, } \\
2002 \text { ) }\end{array}$ & $\begin{array}{l}\text { Fechamento das } \\
\text { edições }\end{array}$ \\
\hline Audiencia & Cativa & & Não-cativa \\
\hline
\end{tabular}

Fonte: Tabela elaborada pelo autor 


\section{DIFERENÇAS ENTRE OS DISCURSOS}

Por que existem as mencionadas diferenças entre os discursos da comunicação da ciência interpares e o discurso da comunicação pública da ciência? No momento, por problema de espaço, apenas expandiremos em algumas dimensões a notícia telegráfica que consta na matriz acima. Em verdade, se observarmos os veículos de comunicação científica, verificaremos a ocorrência de alguma continuidade entre as publicações concernentes à comunicação primária e à secundária Contudo, esses dois tipos (ideais) de comunicação científica se diferenciam por várias razões e devem obedecer, portanto, a diferentes linguagens e estilos. Embora ambos tenham um compromisso com a "verdade" científica, a divulgação pode e precisa despertar a fantasia e a imaginação do leitor como meio de "cativar" seu interesse e garantir sua atenção (Guimarães, 2001).

A comunicação primária admite um receptor cativo, isto é, aquele que por razões profissionais não pode ou não quer se esquivar à recepção da mensagem. O receptor da comunicação secundária, ao contrário, não é cativo. Pode a qualquer momento se esquivar à mensagem sem sofrer qualquer sanção. Esse grau de liberdade da audiência da comunicação científica secundária é uma das razões que faz com que ela se diferencie da comunicação primária com respeito a diversos fatores, inclusive a proporção de sua utilização das diferentes funções da linguagem (Jakobson, 1969). As mensagens da comunicação secundária demandam, portanto, uma utilização mais intensa de determinadas funções menos exercidas na comunicação primária. Esta é uma das razões, possivelmente, da demanda de uma competência específica do divulgador científico nem sempre disponível ao cientista. Um outro aspecto da comunicação primária ou interpares dos cientistas é a aparente ausência ou falta da necessidade da ocorrência de recursos retóricos em suas mensagens. Se uma das características do discurso científico em relação à "realidade" é a sua verossimilhança, esse discurso teria, antes de tudo, uma característica apodítica, dispensando qualquer recurso retórico. Assim, paradoxalmente, um recurso retórico do discurso científico, para impor sua verossimilhança, é considerá-lo como um discurso predominantemente apodítico, isto é, carente de recursos de persuasão.

A comunicação primária tem ainda a necessidade de utilizar uma linguagem monossêmica. A univocidade dos significados dos signos e dos semas científicos é uma condição para atender uma das condições primordiais das teorias científicas: a possibilidade de sua retificação ou ratificação por meio do controle experimental. Como repetir um experimento ou uma observação, se o protocolo dos procedimentos para essas operações contém signos ambíguos ou equívocos? Em verdade, mesmo sendo unívocas e utilizando em maior proporção a função referencial da linguagem, as comunicações primárias demandam também certo uso das demais funções ou de alguns recursos retóricos (Perelman; Olbrechts-Tyteca, 1983). 
O divulgador necessita "traduzir" uma mensagem formulada num código específico e unívoco, cujo acesso demanda um determinado tempo de aprendizado de seu usuário, o cientista, da linguagem natural, polissêmica e ambígua. Esta tarefa é, como se vê, complexa e, às vezes, impossível (Roqueplo, 1974).

O discurso de divulgação deve utilizar os recursos convenientes a cada caso: as figuras de retórica e funções de linguagem adequadas. Mas esse discurso não deve se limitar a fatos, descobertas ou teorias da ciência. Para verdadeiramente facilitar o advento de uma cultura científica da população, deve também relembrar episódios da história da ciência, não só os caminhos, mas os descaminhos das descobertas, as bifurcações históricas, enfim levar ao público leigo uma ideia não só das cooperações, mas também dos conflitos. A ciência deve ser vista não como uma empresa intelectualmente asséptica, mas imersa no contexto histórico, social e político.

\section{Dimensão ontológica}

A dimensão ontológica, que se traduz num "obstáculo epistemológico" (Bachelard, 1996) à divulgação, consiste no seguinte:

1. O cientista comunica o resultado de suas pesquisas em linguagem na qual denota seus objetos (conceitos) e a relação entre eles (hipóteses, teorias, leis) etc. Nesse momento, sua posição filosófica (realista, convencionalista, construtivista) não influencia a crença na existência real desses objetos. Isto significa que, na prática de sua atividade e na comunicação dos resultados de sua pesquisa, todo cientista é realista, isto é, age e comunica como se seus objetos tivessem existência independente do observador? .

2. O realismo do público, em geral, se manifesta pela crença nos objetos correntes do senso comum. Em suma, uma mesa é uma mesa com existência autônoma no espaço e no tempo, assim como todos os objetos em sua localização espaço-temporal.

3. A comunicação da ciência ao público, embora de um realismo (dos objetos científicos) a outro (dos objetos do senso comum), se ressente de uma tradução difícil, quiçá impossível, entre esses dois planos. Esse fato Bachelard denominou "obstáculo epistemológico". O obstáculo ontológico à divulgação científica consiste então na 'tradução' do conceito do objeto científico para seu correlato em linguagem ordinária.

\footnotetext{
${ }^{8}$ A palavra "traduzir", no seu sentido de tradução de uma língua natural a outra, é inadequada para significar a passagem da comunicação primária para a comunicação secundaria. Por isso alguns autores preferem a expressão "tradução intersemiótica" (Jacobi; Schieli, 1988).

${ }^{9}$ Claro que essa posição deve ser matizada quando se trata de ciências humanas.
} 


\section{Dimensão linguística}

Os cientistas se comunicam entre si mediante códigos e linguagens, que, em geral, são específicos para cada especialidade. Boa parte do preparo dos pesquisadores consiste no aprendizado dos conceitos e a sintaxe e semântica desses códigos e dessas linguagens. Tratando-se de saberes que, de algum modo, como vimos, devem ser retificados ou ratificados pela experiência, é fácil de se compreender a conveniência da univocidade de significado dos termos e conceitos utilizados na comunicação primária. O estabelecimento dessa univocidade pode anunciar a criação de uma ciência. O nascimento da química moderna, ao final do século XVIII, com as descobertas de Lavoisier, compreendeu uma nova nomenclatura para os elementos e compostos químicos. Esse fato não demorou nada a ser compreendido pelos próprios pesquisadores da época. $O$ nascimento da química moderna foi possível graças à substituição de procedimentos, às vezes secretos, por procedimentos universais que, necessariamente, precisavam ser baseados numa linguagem também universal (Lindberg; Westman, 1990, p. 367-396).

Os pesquisadores de toda ciência bem estabelecida se comunicam entre si por meio de uma linguagem híbrida que contém tanto termos da linguagem natural como termos da linguagem específica. Cada cientista determina, numa certa medida, essa proporção, o que acaba, segundo Granger (1974, p. 44), por caracterizar seu próprio estilo. Mas a própria linguagem natural opera com várias funções e a proporção com que essas funções comparecem, respectivamente, nas linguagens naturais e nas linguagens especializadas varia e este será um dos parâmetros para diferenciar a comunicação primária da secundária.

A não-catividade da audiência da comunicação científica secundária é uma das razões que faz com que ela se diferencie, em alguns aspectos, da comunicação primária. Se o fator persuasivo se faz presente, tanto na CP como na CS, na CP a persuasão é circunscrita ao mérito do contexto da justificação da produção científica. Na CS o contexto de justificação é inacessível à audiência e, portanto, a persuasão envolve recursos retóricos estranhos aos méritos puramente científicos da produção.

\section{Funções da linguagem}

As funções das linguagens naturais têm sido classificadas pelos estudiosos em algumas categorias básicas. Uma das classificações mais completas em uso é a de Jakobson (1969). Esse autor catalogou seis funções da linguagem: 1) a função referencial, centrada no contexto; 2) a função emotiva, centrada no remetente; 3) a função conativa ou imperativa, centrada no destinatário; 4) a função fática, que funciona como um cimento social; é um tipo de função na qual os traços de coesão social são criados pela mera troca de palavras, saudações ou conversas apenas sociais; 5) a função poética ou estética, centrada na própria forma do significante da mensagem; 6) final- 
mente, a função metalinguística, quando a mensagem fala de si própria. Novamente a não-catividade da audiência da comunicação científica secundária é uma das razões que faz com que ela se diferencie da comunicação primária também com respeito à proporção de sua utilização das diferentes funções da linguagem. Quanto às funções da linguagem descritas por Jakobson, verificamos que na comunicação primária tem relevância a função referencial. Já a comunicação secundária necessita que sua linguagem exerça também as funções emotiva, poética e fática, importantes nas mensagens de cunho persuasivo. Nas mensagens primárias é predominante a função referencial. Isto torna essas mensagens, até certo ponto, invariantes para toda a estratégia de tradução. A comunicação científica primária e a secundária se diferenciam por várias razões e devem obedecer, portanto, a diferentes linguagens e estilos. Embora ambas tenham um compromisso com a "verdade" científica, a divulgação pode e precisa despertar a fantasia e a imaginação do leitor como meio de "cativar" seu interesse e garantir sua atenção.

\section{Dimensão semiótica (signos)}

A comunicação primária tem ainda a necessidade de utilizar uma linguagem monossêmica. A univocidade dos significados dos signos e dos semas científicos é uma condição para atender uma das condições primordiais das teorias científicas: a possibilidade de sua retificação ou ratificação por meio do controle experimental. Como repetir um experimento ou uma observação se o protocolo dos procedimentos para essas operações contém signos ambíguos ou equívocos? Em verdade, o estabelecimento da univocidade e universalidade dos conceitos científicos pode anunciar a criação de uma ciência ${ }^{10}$. Na realidade, mesmo sendo unívocas e utilizando em maior proporção a função referencial da linguagem, as comunicações primárias demandam também um certo uso das demais funções ou dos recursos retóricos (Perelman; Olbrechts-Tyteca, 1983, p. 22-23).

De qualquer forma, podemos dizer que, pelo menos, os signos monossêmicos preponderam muito mais nas comunicações primárias do que nas secundárias. Os signos monossêmicos que representam conceitos científicos são, às vezes, construídos especificamente para atender objetivos da teoria e, outras vezes, construídos a partir de signos da linguagem natural menos unívocos e precisos. Assim, por exemplo, a sensação de calor e frio é traduzida pelo conceito científico de temperatura definido a partir de seu modo de aferição objetiva.

\section{Semiótica denotativa e conotativa}

No trânsito da comunicação primária para a secundária podem ser detectados elementos retóricos que desvelam fragmentos ideológicos correlatos. Valemo-nos das definições e da notação de Louis Hjelmslev (1975, p. 185-219), retomada por Roland Barthes (1971). Assim, utilizando a notação SE = Significante e SO = Significado,

\footnotetext{
10 Como já mencionamos, foi o que ocorreu na criação da química moderna no final do século XVIII.
} 


\begin{tabular}{|c|c|c|c|}
\hline $\begin{array}{c}\text { Semiótica } \\
\text { denotativa } \\
\text { (Sistema real) }\end{array}$ & $\begin{array}{c}\mathrm{SE}_{1}=\text { Discurso } \\
\text { científico: } \\
\text { Fórmulas, enuncia- } \\
\text { dos, teorias, leis }\end{array}$ & $\begin{array}{c}\mathrm{SO}_{1}=\text { Fenômenos e } \\
\text { suas inter-relações }\end{array}$ & $\begin{array}{c}\text { Comunicação } \\
\text { primária (CP) }\end{array}$ \\
\hline
\end{tabular}

podemos considerar esta semiótica denotativa como conteúdo $\mathrm{SO}_{2}$ de um segundo discurso metalingüístico, correspondente à comunicação secundária:

\begin{tabular}{|c|c|c|c|c|}
\hline \multirow{2}{*}{ Metalinguagem } & \multirow{2}{*}{ SE $_{2}$} & SO $_{2}$ & $\begin{array}{c}\text { Hjelmslev (1975, } \\
\text { p. 212-219) }\end{array}$ & $\begin{array}{c}\text { Comunicação } \\
\text { secundária(CS) }\end{array}$ \\
\cline { 3 - 4 } & SE $_{1}$ & SO $_{1}$ & \\
\hline
\end{tabular}

Neste esquema, $\mathrm{SE}_{2}$ seria o significante do discurso da divulgação científica, equivalente a uma metalinguagem do discurso da ciência. A retórica sobreposta a esta metalinguagem seria a conotação:

\begin{tabular}{|c|c|c|c|c|}
\hline Conotação & $\mathbf{S E}_{3}=$ Retórica & $\mathrm{SO}_{3}=\mathrm{F}$ & deologia & \multirow{3}{*}{ Barthes, 1974} \\
\hline \multirow{2}{*}{ Metalinguagem } & \multirow{2}{*}{$\mathrm{SE}_{2}$} & \multicolumn{2}{|c|}{$\mathrm{SO}_{2}$} & \\
\hline & & $\mathrm{SE}_{1}$ & $\mathrm{SO}_{1}$ & \\
\hline
\end{tabular}

Este procedimento de superelevação dos códigos corresponde a possibilidades preexistentes nos universos simbólicos dos intervenientes nos processos comunicacionais. Todo esse conjunto configura, num sentido amplo, o termo código (Epstein, 1993, p. 83-91) como o próprio universo simbólico dos participantes. A retórica, suas figuras e seus procedimentos vistos como significantes correspondem, como significado, ao termo "ideologia" em seu sentido fraco (Bobbio; Matteuci; Pasquino, 1986, p. 585).

As características acima mencionadas da comunicação primária e secundária configuram "tipos ideais", mas servem como recursos didáticos para estudar e compreender os fenômenos e os obstáculos reais.

\section{Dimensão epistemológica}

O juízo do enunciado científico da comunicação primária é de "verdadeiro" ou "falso" e é atribuição dos detentores do "saber competente", isto é, dos pares. O discurso da comunicação secundária, da popularização da ciência, também carece do aval implícito dos "pares", não quanto à sua verdade, mas quanto à sua verossimilhança. Portanto o juízo do discurso da divulgação científica 
é apenas parcialmente (enquanto fiel à fonte primária) o de "verdadeiro" ou "falso". Sobreposta a essa fidelidade há a sua adequação a certos objetivos. Sua eficácia depende de recursos retóricos e das funções estética, fática e persuasiva da linguagem. Sua "verdade" pragmática, tal como a do discurso publicitário, é aferida, em certa medida, por sua capacidade de cativar e persuadir seu público.

\section{Saber competente}

Esse termo, cuja análise e crítica cabe à sociologia da ciência, de um lado, opera como um aval nas relações entre os cientistas, inclusive sancionando e legitimando a comunicação primária por meio da "chamada revisão pelos pares" a que esta comunicação está sujeita. Já na comunicação secundária pelo mediador, a imagem do saber competente pode introduzir obstáculos nas relações entre cientistas e divulgadores; sensíveis os segundos à hegemonia do saber dos primeiros. O cientista detém o saber competente em sua área específica. A sua fala provém de um emissor autorizado (Chauí, 1986, p. 11). Esse emissor autorizado é o especialista, aquele que possui, reconhecida e legitimamente, determinados conhecimentos que o autorizam a falar. Neste aspecto a interface da relação entre o cientista e o divulgador revela uma assimetria, pois apenas um dos lados, o do cientista, detém o saber competente. A "competência" do jornalista raramente atinge o tema objeto da comunicação. O jornalista ou divulgador necessita, portanto, do aval do cientista quando o cita. Mas a mensagem do divulgador, incorporando características fáticas, estéticas e persuasivas, pode desagradar a sua fonte, o cientista entrevistado.

\section{CONSIDERAÇÕES FINAIS}

As diferenças entre os discursos da comunicação primária e secundária da ciência, demarcadas segundo a matriz multidisciplinar acima disposta, e também de algumas razões dessas diferenças, a rigor não passam de hipóteses, por verossímeis que possam parecer. Será, porém, que essas diferenças subsistem concretamente nesses discursos? A nossa hipótese inicial é que as características (ou pelo menos algumas delas) de CP e CS descritas pela matriz multidisciplinar, de algum modo, já estão embutidas nas práticas dos produtores (CP) e dos divulgadores (CS). Como tem acontecido em outros casos na história da ciência, e notadamente nas ciências da comunicação, a prática precede a teoria ${ }^{11}$. Para verificar essas hipóteses será necessária uma verificação empírica.

Para tanto, sugerimos amostras de materiais de comunicação secundária onde haja referência explícita às fontes primárias consultadas. (Chamaremos esse material de "artigos casados"). Dos periódicos de divulgação científica existentes entre nós, alguns pelo menos, costumam apresentar matérias com fontes explicitamente mencionadas.

\footnotetext{
${ }^{11}$ Como resume genialmente um personagem de Guimarães Rosa: "O que um dia vou saber, não sabendo eu já sabia"
} 
Ciência Hoje, editada pela SBPC (Sociedade Brasileira pelo Progresso da Ciência), Scientific American do Brasil, editada pela Duetto, e o jornal O Estado de S. Paulo são alguns exemplos. As fontes citadas do material primário são os periódicos Nature, Science e Jama (Journal of the American Medical Association), se bem que outros periódicos também são citados, inclusive alguns nacionais. Alguns cientistas que escrevem artigos de divulgação científica em jornais da grande imprensa também mencionam suas fontes ${ }^{12}$.

Sugerimos, para um estudo-piloto, a seleção de cerca de 24 conjuntos desses "artigos casados", com distribuição variada dentro de um período de vários anos.

\section{Exemplos de artigos casados}

\begin{tabular}{|c|c|c|c|c|c|}
\hline \multicolumn{3}{|c|}{ Comunicação Primária (CP) } & \multicolumn{3}{|c|}{ Comunicação secundária (CS) } \\
\hline Periódico & Data & $\begin{array}{c}\text { Título do } \\
\text { artigo }\end{array}$ & Periódico & Data & $\begin{array}{c}\text { Título do } \\
\text { artigo }\end{array}$ \\
\hline Science & $\begin{array}{l}\text { 26/08/2005, } \\
\text { p. } 1357-1360\end{array}$ & $\begin{array}{l}\text { Inner core diffe- } \\
\text { rential motion } \\
\text { confirmed... }\end{array}$ & $\begin{array}{l}\text { O Estado de } \\
\text { S. Paulo }\end{array}$ & $\begin{array}{l}\text { 28/09/2005p. } \\
\text { A20 }\end{array}$ & $\begin{array}{l}\text { Os dias são } \\
\text { mais curtos } \\
\text { no centro da- } \\
\text { Terra }\end{array}$ \\
\hline Jama & $\begin{array}{l}\text { 11/08/2004, } \\
\text { v. 09, p.715 }\end{array}$ & $\begin{array}{l}\text { Safety and im- } \\
\text { munogenity }\end{array}$ & Ciência Hoje & 09/04/2007 & $\begin{array}{l}\mathrm{M} \text { contra a fe- } \\
\text { bre reumática }\end{array}$ \\
\hline Science & $\begin{array}{l}\text { 10/08/2001, } \\
\text { p.1048 }\end{array}$ & $\begin{array}{l}\text { Lateral gene } \\
\text { transfer... }\end{array}$ & $\begin{array}{l}\text { Scientific } \\
\text { American do } \\
\text { Brasil }\end{array}$ & $\begin{array}{l}\text { Jan. } 2005, \\
\text { p. } 60-64\end{array}$ & $\begin{array}{l}\text { Ameaça } \\
\text { fantasma }\end{array}$ \\
\hline Science & $\begin{array}{l}02 / 03 / 2007, \\
\text { p. 1239-1243 } \\
\end{array}$ & $\begin{array}{l}\text { Mystery towers } \\
\text { an ancient.... }\end{array}$ & Ciência Hoje & $\begin{array}{l}\text { Jul. } 2007, \\
\text { p. 11-13 } \\
\end{array}$ & $\begin{array}{l}\text { O mais antigo } \\
\text { observatório }\end{array}$ \\
\hline Nature & $\begin{array}{l}2003, \text { v. } 422, \\
\text { p. } 759\end{array}$ & $\begin{array}{l}\text { Molecular } \\
\text { motors }\end{array}$ & Ciência Hoje & $\begin{array}{l}\text { Set. 2006, } \\
\text { p. 26-31 }\end{array}$ & $\begin{array}{l}\text { Motores } \\
\text { moleculares }\end{array}$ \\
\hline Nature & $\begin{array}{l}\text { 04/08/005, } \\
\text { v. } 436, \text { p.641 }\end{array}$ & $\begin{array}{l}\text { Dogs cloned } \\
\text { from adult } \\
\text { somatic cells }\end{array}$ & $\begin{array}{l}\text { O Estado de } \\
\text { S. Paulo }\end{array}$ & $\begin{array}{l}\text { 10/08/2005 } \\
\text { p. A16 }\end{array}$ & $\begin{array}{l}\text { Snuppy, uma } \\
\text { prova do con- } \\
\text { ceito }\end{array}$ \\
\hline Nature & $\begin{array}{l}\text { 14/02/2008, } \\
\text { v. } 818, \text { p. } 821\end{array}$ & $\begin{array}{l}\text { Primitive early } \\
\text { bat from Wio- } \\
\text { ming and... }\end{array}$ & Ciencia Hoje & Mar. 2008 & $\begin{array}{l}\text { O sonar dos } \\
\text { morcegos }\end{array}$ \\
\hline
\end{tabular}

\footnotetext{
12 Um deles é o biólogo Fernando Reinach e um exemplo é o artigo publicado no jornal "O Estado de São Paulo" de 28/09/05 p. A-20 onde é mencionada fonte: A revista Science publicada pela AAAS (American Association for the Advancement of Science) Vol.309, 26/08/05. O autor é colaborador permanente do jornal de modo que seu material é freqüente e de muito fácil acesso.
} 


\begin{tabular}{|c|l|l|l|l|l|}
\hline Nature & $\begin{array}{l}31 / 01 / 2008, \\
\text { p. } 509\end{array}$ & $\begin{array}{l}\text { Reviewer } \\
\text { leaked Avandia } \\
\text { study to drug } \\
\text { firm... }\end{array}$ & Ciencia Hoje & $\begin{array}{l}\text { Mar. 2008, } \\
\text { n. 20 }\end{array}$ & Sintonia fina \\
\hline Science & $04 / 01 / 2008$ & $\begin{array}{l}\text { A mosaic } \\
\text { of chemical } \\
\text { evolution... }\end{array}$ & $\begin{array}{l}\text { O Estado de } \\
\text { S.Paulo }\end{array}$ & $\begin{array}{l}\text { 13/03/2008,p. } \\
\text { A 26 }\end{array}$ & $\begin{array}{l}\text { Insetos envol- } \\
\text { vidos em uma } \\
\text { corrida arma- } \\
\text { mentista }\end{array}$ \\
\hline Science & $\begin{array}{l}15 / 11 / 1998, \\
\text { p. } 115-125\end{array}$ & $\begin{array}{l}\text { The afrian wild } \\
\text { ass (Equus) }\end{array}$ & $\begin{array}{l}\text { Scientific } \\
\text { American of } \\
\text { Brasil }\end{array}$ & 01/04/2005 & $\begin{array}{l}\text { Equideos em } \\
\text { perigo }\end{array}$ \\
\hline Science & $\begin{array}{l}23 / 02 / 2007, \text { p. } \\
1122-1126\end{array}$ & $\begin{array}{l}\text { Redifining the } \\
\text { age of Clois..... }\end{array}$ & Ciencia Hoje & Jul. 2007 & $\begin{array}{l}\text { Povoamento } \\
\text { da América }\end{array}$ \\
\hline Nature & $\begin{array}{l}20 / 10 / 2005, \\
\text { p. 1070-1071 }\end{array}$ & $\begin{array}{l}\text { Cash interests } \\
\text { taint drug advice }\end{array}$ & $\begin{array}{l}\text { O Estado de } \\
\text { S. Paulo }\end{array}$ & $\begin{array}{l}\text { A20/10/2005,p. } \\
\text { A22 }\end{array}$ & $\begin{array}{l}\text { ceitam o que } \\
\text { a indstria } \\
\text { manda, diz } \\
\text { estudo }\end{array}$ \\
\hline
\end{tabular}

Como se pode verificar acima, o espaço de tempo entre a publicação primária e a secundária varia de alguns dias a meses e até anos. Essa variedade permitirá a verificação de características que permanecem. A análise comparativa empregará os instrumentos mais adequados.

Assim para a comparação na dimensão linguística nos valeremos da análise de conteúdo para comparação quantitativa entre os signos (palavras) unívocos e especializados e os signos da linguagem natural em cada amostra dos discursos primários e secundários. O mesmo instrumento será utilizado para aferir a frequência relativa dos signos icônicos - gráficos, esquemas, fotografias - em cada discurso. Já para a aferição das semióticas denotativa e conotativa, bem como da presença de recursos retóricos, usaremos a análise do discurso. Outros recursos de análise considerados adequados a cada dimensão serão utilizados, inclusive eventuais entrevistas com os autores das matérias de comunicação secundária.

Um segundo aspecto que pretendemos verificar é um estudo comparativo entre a frequência das diferenças dos fatores mencionados na matriz multidisciplinar quando os artigos casados se referirem às ciências da natureza e às ciências humanas.

Um terceiro aspecto, mais sutil, é a fidelidade da comunicação secundária ao ideário e à filiação disciplinar da comunicação primária. Constatamos esse fato em trabalho no qual algum viés proveniente eventualmente de uma formação profissional do divulgador consegue desviar a atenção de um caráter essencialmente original da pesquisa primária no paradigma da sociobiologia para uma conotação mais banal numa vertente psicológica (Epstein; Bertol, 2005). Os protocolos para a efetivação da análise comparativa ainda não estão finalizados. 


\section{REFERÊNCIAS}

BACHELARD, Gaston. O primeiro obstáculo: a experiência primeira. In: A formação do espírito científico. Rio de Janeiro: Contraponto, 1996. p. 29-68.

BARTHES, R. Elementos de semiologia. São Paulo: Cultrix, 1971.

BELSEY, Andrew; CHADWICK, Ruth. Ethical issues in journalism and the media. London: Routledge, 1992.

BOBBIO, Norberto; MATTEUCI, Nicola; PASQUINO, Gianfranco. Dicionário de política. Brasília: Ed. UnB, 1986.

BROCKMAN, John. The third culture. Nova York: Simon \& Shuster, 1995.

CHAUI, Marilena Conformismo e resistência, São Paulo: Brasiliense, 1986.

COLLINS, Harry M.; EVANS, Robert. The third wave of science studies: studies of expertise and experience. Social Studies of Science, Sage, v. 32, n. 2, p. 235-229. abr.2002.

DAWKINS, Richard. A escalada do monte improvável. São Paulo: Cia. Das Letras, 1998.

ECO, Umberto. Tratado geral de semiótica. São Paulo: Perspectiva, 1980.

EPSTEIN, Isaac. Gramática do poder. São Paulo: Ática, 1993.

Quando um fato se transforma em notícia no jornalismo e na ciência. Comunicação \& Sociedade, São Bernardo do Campo (SP), Umesp, n. 47, p. 159-182, 2007.

EPSTEIN, Isaac; BERTOL Sônia. Caminho das pedras: a difícil arte de comunicar a ciência para o público. Comunicação \& Sociedade, São Bernardo do Campo (SP), Umesp, n. 43, p. 11-28, 2005.

GARDNER, Martin. WAP, SAP, PAP, and FAP. In: The night is large. Nova York: St. Martin's Press, 1996. p. 40-49.

GLEISER, Marcelo. A dança do universo. São Paulo: Cia das Letras, 1997.

GRANGER, Gilles-Gaston. Filosofia do estilo. São Paulo: Perspectiva, 1974.

GREGORY, Jane; MILLER, Steve. Science in public: communication, culture and credibility. Nova York: Plenum Press, 1998.

GUIMARÃES, Eduardo (Org.). Produção e circulação do conhecimento. Campinas: Pontes, 2001.

HARTZ, Jim; CHAPELL, Rick. Worlds apart: how the distance between science and journalism threatens America's future. Hashville: First Amendement Center, 1997.

HJELMSLEV, Louis P. Prolegômenos a uma teoria da linguagem. São Paulo: Ed. Abril, v. XLIX, 1975.

HONDERICH, Ted (Ed.). The Oxford companion to philosophy. Nova York: Oxford University Press, 1995.

JACOBI, Daniel; SCHIELE, Bernard. Vulgariser la science. Seyssel: Ed. Ch. Vallon, 1988. 
JAKOBSON, Roman. Linguística e comunicação. São Paulo: Cultrix, 1969.

KUHN, Thomas. Estrutura das revoluções cientificas. São Paulo: Perspectiva, 1978.

LINDBERG, David C.; WESTMAN, Robert S. Reappraisals of the scientific revolution. Cambridge: University Press, 1990.

MARCUS, Solomon. Fifty-two opositions between scientific and poetic communication. In: CHERRY, Colin (Ed.). Pragmatics aspects of human communication. Boston / Doordrecht (Holland): D. Reidel, 1974.

MERTON, Robert K. Sociología de la ciencia. Madrid: Alianza Editorial, 1977.

NAGEL, Ernest. La estructura de la ciencia. Buenos Aires: Paidós, 1971.

PERELMAN, Chaim; OLBRECHTS-TYTECA, Lucy. [1970]. Traité de l'argumentation. Bruxelas: Éd. de l'Université de Bruxelles, 1983.

POPPER, Karl. Conjectures and refutations. Londres: Routledge and Kegan Paul, 1965.

La lógica de la investigación cientifica. Madrid: Tecnos, 1967.

Experience and prediction: Phoenix: University of Chicago Press, 1961.

ROQUEPLO. Philippe. Le partage du savoir. Paris: Seuil, 1974.

ROSA, Guimarães, Tutameia: terceiras estórias (1967):

SAGAN, Carl. Cosmos: Nova York: Ballantine Books, 1980.

The demon-haunted world. Nova York: Random House, 1995.

WOLF, Mauro. La investigación de la comunicación de masas. Barcelona: Paidós, 1990.

Recebido em: 20.04.2012 / Aceito em: 20.05.2012 